\title{
A DIALÉTICA DO CÂNONE LITERÁRIO SOB A ÓTICA DO CONCEITO DE EXCLUSÃO: CONTRAPONTOS FILOSÓFICOS E ENSINO DE LITERATURA ${ }^{1}$
}

\author{
João Luis Pereira Ourique ${ }^{2}$ \\ Priscila Monteiro Chaves ${ }^{3}$
}

\begin{abstract}
Resumo: Impulsionado pela constante discussão acerca do cânone literário, o presente trabalho se propõe a refletir sobre o caráter excludente que este pode tomar se mal interpretado. Para atender a esta finalidade, a formação do sujeito-leitor é apresentada como uma possibilidade de resistência aos dogmatismos impostos nessa realidade. Apoiado nas teorias de Paulo Freire e Theodor Adorno, fundamentalmente - e com o pressuposto que 0 cânone literário não deve ser tomado como verdade absoluta, e sim um dado interpretativo pretende-se problematizar as concepções de leitura e cultura, especialmente o papel da crítica, no contexto escolar, evidenciando as contradições e idiossincrasias presentes no discurso educacional na área do ensino da literatura.
\end{abstract}

Palavras-chave: cânone literário; exclusão; formação do leitor; cultura.

Résumé : Poussé par un débat permanent sur le canon littéraire, cet article se propose de réfléchir sur le caractère d'exclusion qui il peut acquérir quand mal compris. À cette fin, la formation du sujet-lecteur est présentée comme une possibilité de résistance aux dogmatismes dans cette réalité. Selon les théories de Paulo Freire et Theodor Adorno, fondamentalement en accord avec l'hypothèse que le canon littéraire ne doit pas être compris comme une vérité absolue, mais comme une interprétation - ce texte vise à problématiser les conceptions de lecture et de culture, en particulier le rôle de la critique dans le contexte scolaire, en soulignant les contradictions et les particularités présentes dans le discours éducatif de l'enseignement de la littérature.

Mots-clés: canon littéraire, exclusion; formation du lecteur; culture.

\section{Introdução}

Segundo algumas reflexões advindas da teoria freiriana, quando se fala em inclusão ${ }^{4}$ de um grupo marginalizado a um sistema, este está longe de ser

\footnotetext{
${ }^{1}$ Uma primeira versão desse trabalho foi apresentada no IV Seminário Nacional de Filosofia e Educação: Confluências, realizado no período de 21 a 23 de maio de 2012 na Universidade Federal de Santa Maria - UFSM.

${ }_{3}^{2}$ Professor Adjunto do Centro de Letras e Comunicação da Universidade Federal de Pelotas.

3 Mestranda do Programa de Pós-Graduação em Educação da Universidade Federal de Pelotas.

4 Bastante usual no contexto educacional da atualidade bem como nas mais diversas produções acadêmicas são os conceitos de inclusão e exclusão. Porém, justamente por terem se tornado termos de utilização bastante disseminados, sofrem com o pagamento do alto preço da indefinição, como se estas fossem palavras místicas que tudo explicassem são encaixadas
} 
um processo de libertação, visto que, ainda para esta mesma teoria, a solução para aqueles que estão à margem de estaria em uma integração à sociedade. Porém, em analisar de perto tal situação, é possível constatar que estes não estavam de fora no que compete à formação de tal sistema, já que de acordo com seu caráter opressor, sempre houve a tentativa de incluí-los, contudo, transformando-os em seres para outro.

$\mathrm{Na}$ formação do sujeito-leitor, esta problemática se mostra bastante presente também, visto que tal formação se configura de maneira desigual às distintas classes sociais, tanto em seu princípio, isto é, no momento usualmente chamado de alfabetização, bem como nos próximos ciclos e (talvez principalmente) no ensino de literatura, visto que a leitura - em especial a literária - pode ser entendida e percebida como um fator importante para a percepção de uma consciência histórica. No entanto, o trabalho com textos literários nos espaços formais de ensino acaba por relegar a um segundo plano os aspectos ligados a essa consciência que é base para a formação cultural.

$\mathrm{O}$ ato de ler, para grande parte dos adolescentes, ainda é sinônimo de "ler no contexto escolar", ler porque precisa realizar um exame, elaborar um projeto, discutir um assunto. Tal situação parece agravar-se quando a leitura Ihes é imposta, quando estes alunos precisam ler uma série de produções nas quais não têm oportunidade de opinar. Por vezes, estas leituras não lhes dizem nada, e tampouco Ihes são trabalhadas pelo caminho da formação de um sentido, um significado. Quem ultimamente vem sendo incumbido de fazer tal seleção? Quais são os motivos que se tem para que a escola tenha optado por algumas e não outras obras?

\section{De sujeitos formados e (de) formações: a leitura literária}

As escolhas são os elementos que sustentam os valores de determinada sociedade em uma situação histórica e cultural específica; ainda que seja

aqui e ali, por vezes descomprometidamente, distantes de suas radicalidades (MARTINS apud OLIVEIRA). Desta forma, tal conceito não será aqui definido, somente problematizado, cotejando-o com o ensino de literatura. 
reconhecida sua pluralidade, sempre há uma tentativa de nivelar alguns desses aspectos em prol de uma suposta ordenação desses mesmos valores. O texto de Mario Quintana, $O$ nariz coletivo, apresenta uma crítica às visões totalizantes e totalitárias que excluem as diferenças e fazem com que as pessoas sejam iguais em sua indiferença.

Nada mais deprimente do que esses retratos de família em que todos têm o mesmo nariz (será postiço?) e onde todas aquelas caras parece que estão pensando: "Mas como somos iguais, como somos animais!"

Não há de ser nada. Há um anonimato ainda mais sutil. E mais grave. Quando folheamos revistas antigas, espanta-nos que todas aquelas pessoas que aparecem nas fotografias tivessem a mesma expressão. Vai ver que todos pensavam igual! Era a cara da época. Era a cara de fora. Ninguém tinha a cara de dentro. "Também seremos assim?" - indagas agora, na maior frustração. Pergunta supérflua. Devias inquirir: "Serei assim?". E trata, antes de substituir a tua cara coletiva por uma fisionomia própria. Depois conversaremos.

Há outras conotações, como hoje se diz. Por exemplo: nos Estados totalitários todas as pessoas têm a mesma cara. A grande manada. $O$ rebanho único. $E$ se caso aparece um bicho diferente, a solução é simples: caça-se. (QUINTANA, 2005, p. 326-327).

Quando se fala na habilidade de "ler literatura", a temática parece abordar uma constante discussão, ou seja, não basta apenas pensar com as estruturas advindas de um modelo historiográfico - que situa as obras em um determinado período histórico, enfatizando estilos individuais e de época - ou de uma imanência textual em que as marcas textuais se fecham à interpretação. É necessário, ao lado dessas ferramentas, pensar na perspectiva gadameriana de que o leitor carrega (ou melhor, articulando com as palavras de Quintana, deveria carregar) valores não niveladores, antes o contrário, conflituosos, que são terreno fértil para a indagação e o questionamento.

Normalmente orientados pelo projeto iluminista de suspensão de todos os pressupostos e de autonomia radical da razão, pensamos que um conhecimento só encontra seu ponto de legitimidade quando zeramos por assim dizer nossas crenças. O problema de tal pressuposto, contudo, é que ele passa completamente ao largo do que propriamente acontece em todo e qualquer processo hermenêutico. $\mathrm{Na}$ verdade, não é apenas impossível produzir tal suspensão de nossos 
pressupostos; se realmente conseguíssemos alcançar algo assim, o que teríamos seria por fim ao mesmo tempo indesejável. A suspensão de nossos pressupostos significariam propriamente uma dissolução de toda a orientação prévia e de toda a expectativa de sentido em relação ao que se deveria interpretar. Sem tal orientação e tal expectativa, porém, não teríamos nem mesmo como nos aproximar do que deveria ser interpretado, uma vez que é essa orientação e essa expectativa que conduzem a aproximação. (CASANOVA, In: GADAMER, 2010, p. XI).

Por vezes, o educando envergonha-se em ler uma listagem de obras consideradas cânones literários e perceber que não conhece sequer uma delas, sentindo-se menos "culto" por não ter tido contato algum com livros considerados por ele "leitura difícil". Se tal constrangimento ocorre é possível que muitos educadores não estejam esclarecendo que os considerados "melhores" nem sempre são melhores para todas as pessoas e que em meio a tais avaliações perpassam pressupostos teóricos, os quais enumeram as instâncias de legitimação daquele texto. Tal atitude acaba por não reconhecer e valorizar o processo mesmo de formação do leitor, inibindo a capacidade interpretativa pelo desconhecimento de determinadas obras e autores (é importante mencionar que não está em jogo aqui uma apologia contra as obras clássicas e/ou canônicas, mas sim na limitação imposta aos leitores no ambiente escolar, o que atua como uma forma de exclusão formativa).

A formação do sujeito-leitor é problemática bastante abordada no contexto escolar e juntamente com esta vem à tona toda uma realidade de disparidade social que evidencia diferentes condições de leitura em meios também os mais diversificados. Exemplificando melhor tal preocupação, Soares (2000) já advogava que o acesso ao mundo da cultura escrita vem significando para as camadas populares a aquisição de uma habilidade quase mecânica de codificação/decodificação, ou o acesso a universos fechados arbitrariamente impostos. Dessa forma, para a autora o sistema vem permitindo ao povo que "aprenda a ler", porém não que se torne leitor (grifos nossos).

Essa inquietação da autora vem sendo legitimada em virtude da maneira como são impostas novas teorias e métodos de alfabetização, assim como um cânone que é cobrado às escolas sem preparação alguma, sem que esses mesmos órgãos governamentais que o impuseram dessem ferramentas 
concretas para o professor adotar um conjunto de práticas inerentes a tal conceito, não dando condições para que o educador seja capaz de assumir como seu os projetos institucionais. A periculosidade parece ser maior quando se salienta o alerta de Moraes (1997) sobre a ilusão de mudança de paradigma educacional apenas pela utilização de outras roupagens nas velhas teorias, visto que o aluno permanece na posição de mero espectador do processo de formação. O plano é enganador, principalmente com 0 avassalador avanço das tecnologias, em que a maioria pouco faz para propiciar que o aluno seja sujeito da atividade de leitura.

Theodor Adorno (1996) aponta para uma recusa a essa fácil consciência, produzindo a realização da experiência através de pequenas (e difíceis) expectativas nas quais os perigos e obstáculos não se constituem em uma salvação da história, mas uma rememoração dos encontros com os outros e com o novo. O reconhecimento de que essas expectativas não promoverão uma redenção da história não se vincula ao fato de que somente pode ter uma experiência aquele que tem consciência da sua historicidade. O espaço escolar acaba por barrar essa perspectiva da formação de um sujeito-leitor ao não estabelecer um espaço de interpretação consistente e coerente com seus ideais, que acabam por se transformarem em falácias e clichês que sustentam uma formação deturpada.

Com a elaboração dos PCN's (Parâmetros Curriculares Nacionais) vem sendo cobrado dos professores de Ensino Fundamental e Médio que trabalhem com alguns pré-determinados nomes e gêneros. Devido a tal exigência e aos processos seletivos, que são os principais meios de ingresso à academia, há uma grande preocupação em torno do que é ou não considerado bom pela crítica literária. $\mathrm{O}$ que se não for trabalhado de maneira clara e bem justificada pode reforçar a cultura da classe dominada, como sendo a única coerente, a correta, a que deve ser seguida, esquecendo que entre os professores e os alunos existe não apenas temas e programas (FREIRE, 1996).

Pode-se perceber tal realidade no processo de formação do leitor no que compete à problemática do cânone literário ${ }^{5}$. A crítica geralmente estipula o 
que é relevante e importante, porém, tal seleção tem uma limitada gama de justificativas, desta forma, neste processo acaba ficando camuflado o fato de que nem sempre o considerado "melhor" é melhor em todas as culturas e contextos.

Por vezes, são encontrados no contexto escolar ótimos leitores, de portadores de texto pertencentes ao seu mundo imediato, tendo este um alto potencial de reflexão, de crítica e de outras capacidades indispensáveis a uma prática de leitura emancipatória. Porém, como fora dito anteriormente, sentemse constrangidos ao se depararem com uma listagem em que aparecem somente livros jamais lidos por eles, fazendo com que pensem que aquilo que por eles é lido, não é literatura. Mesmo que tais leituras não se sustentem como obras de arte, não é dado ao aluno a capacidade de fazer esse percurso. Nessa dualidade entre a leitura e o objeto desta, esse leitor negligencia - de forma inconsciente na maioria das vezes - o seu percurso formativo e não é capaz de estabelecer parâmetros confiáveis a partir de sua própria interpretação, mantendo as leituras prazerosas e se distanciando das escritas densas e inacessíveis a sua compreensão.

De certa forma esta imposição pode ser considerada uma negação da práxis presente na teoria freiriana, visto que lhe é negado o desenvolvimento desta criticidade, desta reflexão, ou melhor, desta ação pensada, de ser dono de suas escolhas e julgamentos, tendo que se adaptar, sem uma postura crítica, a uma realidade que não é sua, e sim de seu dominador.

A partir destas considerações, vale evocar novamente o que Reis (1992) salienta, pois se entende a necessidade de articular outras formas de leitura, das quais possam resultar novas possibilidades interpretativas, o que demanda uma ativa função do leitor.

É também fundamental lançar mão de outros paradigmas de leitura, estabelecendo o contexto histórico como solo da

um evento histórico, visto ser possível rastrear a sua construção e a sua disseminação. Assim sendo, não é suficiente repassá-lo ou revisá-lo, lendo outros e novos textos, não canônicos e não canonizados, sucedendo os "maiores" pelos "menores". Da mesma maneira que não é suficiente "dilatar o cânon e nele incorporar outras formações discursivas, como a telenovela, o cinema, o cordel, a propaganda, a música popular, os livros didáticos ou infantis, a ficção científica, buscando uma maior representatividade dos discursos culturais. O que é problemático, em síntese, é a própria existência de um cânon, de uma canonização que reduplica as relações injustas que compartimentam a sociedade” (REIS, 1992, p. 76). 
interpretação. Ou seja, está em jogo uma maneira de ler, uma estratégia de leitura que seja capaz de fazer emergir as diferenças, em particular aquelas que conflitem com os sentidos que foram difundidos pela leitura canônica, responsável em última análise pela consagração e perenidade dos monumentos literários e via de regra reforçadora da ideologia dominante, subvertendo, desse modo, a hierarquia embutida em todo o processo (p. 77).

Este quadro anteriormente apontado e evidentemente antidialógico torna-se um dos principais impasses da formação do indivíduo como leitor, já que pode gerar dependência do educando daquele que o instaurou tais valores, em outras palavras, que leituras fará este, a partir do momento que deixar o contexto escolar?

De acordo com a teoria freiriana (1996), poderia este ser uma forma de Invasão Cultural? Caracterizada pelo desrespeito às potencialidades do ser, pela imposição de uma visão de mundo que não a sua, reprimindo suas criatividades e inibindo sua expansão?

Provavelmente a resposta para essas questões seja positiva, haja vista um estabelecimento de uma aliança que acaba por solidificar um modelo consagrado de organização dos conhecimentos sobre literatura. O elenco de autores e obras fixado pelas instituições de ensino determina a pertinência de leitura de textos, servindo como referência constante de qualidade do que será lido.

Ocorre que a fixação desse elenco de autores e obras, de acordo com esse modelo historiográfico, acaba sendo um mecanismo repressor, por excluir do universo escolar uma série de textos que não conseguiram, por uma razão ou outra, a consagração entre a crítica mais autorizada. A reverência a esse elenco, ao mesmo tempo em que sugere a necessidade de cultivar, quase de modo religioso, alguns fundamentos de nossa cultura, ainda que de maneira justa, funciona como um filtro de percepção, que afasta outros horizontes.

As crianças, no início de suas formações como leitoras, já devem ser estimuladas a analisar os portadores de texto com olhar de criticidade, estimuladas a pensar certo $^{6}$ e ter o direito de dizer a sua palavra. O que pode

6 Em sua Pedagogia da Autonomia, Paulo Freire aborda a expressão pensar certo como sinônimo de pensar dialético, um ato crítico e não mecânico. Para o autor, pensar certo não é 
ser visto como um avanço no campo linguístico educacional, já que se encontram nos livros didáticos de ensino de língua materna e literatura ${ }^{7}$ algumas questões que estimulam tal postura crítica do alunado. Como, por exemplo, com a "inocente" e informal questão: "Você indicaria este livro a um amigo? Por quê?" Ainda que este material tenha uma série de fatores a serem melhorados, ele ainda consiste no portador de texto de maior disseminação, pois é por meio do livro didático que grande parte da população tem acesso aos principais nomes da literatura.

O paradigma educacional emergente demanda alunos portadores deste tipo de posicionamento mediante recepção deste material, por isso tal questionamento é de suma importância para a criança. Ela necessita justificar sua escolha, ser dona desta seleção, de julgar se é melhor ou não e o porquê de tal posicionamento, sendo, dessa forma, capaz de desenvolver a autonomia e a criticidade, "habilidades" (se assim for possível apontá-las) das quais tanto carece o contexto escolar atual.

Por tais motivos é que a missão da escola aos poucos vem mudando, buscando uma nova visão de mundo, uma nova educação, e por isso, novos critérios na seleção destes portadores de texto, visto que esse aprendiz não pode mais ser visto como espectador do processo de formação, nem como pertencente a um mundo de sistemas fechados, em outras palavras, não pode seguir dizendo a palavra do outro, "pois a palavra repetida é monologo das consciências que perderam sua identidade, isoladas, imersas na multidão anônima e submissas a um destino que lhes é imposto e que não capazes de superar, com a decisão de um projeto". (FREIRE, 2005, p.20).

Outra finalidade deste trabalho é refletir a respeito de algumas práticas de leitura na sala de aula, e se estas ainda fazem com que o aluno mantenha a sombra do dominador dentro de si (FREIRE, 2005). Infelizmente, parte-se do pressuposto de que ele continua sendo adestrado a realizar uma leitura imposta pela crítica que o domina, (nem sempre bem fundamentada)

tarefa trivial, porque esta demanda "vigilância constante que temos de exercer sobre nós próprios para evitar os simplismos, as facilidades, as incoerências grosseiras" (1996, p. 49).

${ }^{7}$ Não se desenvolverá aqui a discussão da análise dos textos, principalmente dos fragmentos de textos literários em livros didáticos. 
constantemente em meio a esta ação antidialógica. No que compete a esta imposição, Paulo Freire a defende e ao mesmo tempo a confronta:

O professor que desrespeita a curiosidade do educando, o seu gosto estético, a sua inquietude, a sua linguagem, mais precisamente, a sua sintaxe e a sua prosódia [...] tanto quanto o professor que se exime do cumprimento de seu dever de propor limites à liberdade do aluno, que se furta ao dever de [...] estar respeitosamente presente à experiência formadora do educando, transgride os princípios fundamentalmente éticos de nossa existência (1996, p. 59-60).

Contudo, deve ser compreendida também a necessidade de legitimar os critérios de um referencial coletivo, evitando a abertura em excesso de sentidos perdidos, desordenados, sem norma alguma a ser ofertada. Esta parece ser uma incumbência do contexto escolar, o qual adota uma postura de ordenador de valores, deduzindo que aquilo que é melhor para a totalidade, melhor para o outro, coincidirá com o que o é para o educando.

Sendo a escola, antes de tudo uma instituição social, esta deve trabalhar a serviço da vida em comunidade, preocupando-se com os níveis de organização social e principalmente com os interesses que serão defendidos por todos. Neste sentido, as reflexões de John Dewey (1859 - 1952) muito colaboraram, visto que o pensador pressupõe que educação e democracia configuram dois sistemas com níveis equivalentes de manter uma organização.

$\mathrm{Na}$ vida primitiva, podia-se cuidar da continuidade cultural da vida do grupo, ao que parece deixando-se simplesmente que os jovens convivessem com os pais e outras pessoas do grupo, e aprendessem os costumes da vida tribal, à medida que cresciam, pela simples participação na vida em comum. Mas "à medida que as sociedades se tornaram mais complexas em estrutura e recursos", isso já não basta. Parece necessário o "ensino e a aprendizagem formal ou intencional". (KILPATRICK, 2011, p. 82).

Além destes argumentos recém-citados, em uma de suas obras, Experiência e Educação (1971), o pedagogo liberal norte-americano praticou uma crítica categórica à contínua obediência e submissão até então conservadas pela/na escola, considerando ambas impasses para o campo educacional, porém, sem esquecer de que a educação consiste em adquirir 
hábitos de ação em conformidade com as regras e padrões de conduta social pré-estabelecidos.

Para melhor exemplificar tal preocupação, Dewey aponta os livros e especialmente os manuais escolares como materiais a serem utilizados na forma de ferramentas de organização de informação da sociedade, argumentando que:
A história da teoria da educação está marcada pela oposição entre a ideia de que a educação é desenvolvimento de dentro para fora e a de que é formação de fora para dentro; a de que se baseia nos dotes naturais e a de que é um processo de vencer as inclinações naturais e substituí-las por hábitos adquiridos sob pressão externa (DEWEY apud GADOTTI, 1999, p.149, grifos nossos).

Percebe-se assim que existe um conjunto de saberes, bem como de padrões de conduta apropriada, que acabam sendo de necessidade comum a toda uma sociedade. Esses saberes precisam ser valorizados no contexto escolar, ainda que a imposição de cima para baixo oponha-se à expressão e cultivo da individualidade e que, analogamente, a disciplina externa oponha-se à atividade livre, ao aprender pela experiência.

Da mesma maneira que não se tem a intenção de fazer do educando mais um componente de uma massa amorfa, que não se pretende trabalhar a serviço do "enfraquecimento da formação do eu, que de há muito é conhecida da psicologia como 'fraqueza do eu'" (ADORNO, 1995, p.153), não se quer também que o educando caia em um individualismo, e consequentemente em um subjetivismo alienador. Mesmo que o equilíbrio desejado entre a interpretação contextualizada e a reflexão individual não seja nada trivial, ainda é competência da escola que, invariavelmente, acaba por limitar-se em um horizonte já determinado.

\section{Conclusão}

A significação do ensino de literatura parece ser muito mais relevante se este for capaz de oportunizar espaço para que as pessoas reflitam sobre a sua 
formação: tendo em mente a individualidade e o contexto social em que vivem. Formação esta já vislumbrada por Humboldt, que, segundo o paradigma da impossibilidade em que são tecidas as reflexões da teoria adorniana, não consegue unir ambos objetivos, visto que "a ideia de uma espécie de harmonia [...] entre o que funciona socialmente e o homem formado em si mesmo, tornou-se irrealizável" (ADORNO, 1995, p.154).

Talvez o mais coerente não seja o extremo "de se perguntar de onde alguém se considera no direito de decidir a respeito da orientação da educação dos outros" (ADORNO, 1995, p.141), até porque este não é o único nem o mais próximo impasse da formação do homem autônomo, emancipado, conforme a teoria de Immanuel Kant. Um viável principio, pode configurar em, levando em consideração tudo que até aqui foi abordado, repensar a respeito não só da seleção dos textos/obras trabalhadas no ensino de literatura, como também na formação de todo currículo escolar, destacando a relevância de trabalhar-se a partir daquilo que faz parte do conhecimento prévio do aluno. Concernente a esta reflexão, algumas palavras de Mao em diálogo com André Malraux são bastante contributivas: "nous devons enseigner aux masses avec précision ce que nous avons reçu d'elles avec confusion" 8 (MALRAUX apud FREIRE, 2005, p. 97). Palavras estas que apontam a preocupação que o educador deve ter em constituir seu conteúdo a partir das necessidades primeiras do educando. Não somente pela escolha dos conteúdos como também pela elaboração das estratégias de abordagem destes.

Ainda que tal preocupação pareça ser responsável por uma postura pedagógica diferenciada, que possa permitir a realização de maneiras mais significativas de ler com um coletivo, tais práticas podem trazer consigo seu lado perverso: a tentativa de condução e talvez de controle além do desejável naquilo que compete a sua "metamorfose". Atingir esta estabilidade parece ser bastante complicado, visto que, ao mesmo tempo em que se quer evitar uma invasão, dar ao indivíduo validade em excesso, relevância demasiada ao seu meio, pode acarretar em um produto "deficiente", no que concerne ao comprometimento com o sujeito-leitor em formação.

\footnotetext{
${ }^{8}$ Tradução livre: devemos ensinar às massas com precisão o que recebemos delas com confusão.
} 
Em Adorno é possível encontrar uma crítica que evidencia a necessidade da eterna vigilância em torno da própria crítica. O texto de Quintana pode servir exatamente para sustentar outro ponto de vista excludente: o de que somente as diferenças é que importam, elaborando, assim, justificativas para essa nova forma de exclusão. $O$ que ocorre é que 0 modelo de interpretação continua o mesmo, mantendo certas estruturas de domínio, pois o "crítico da cultura mal consegue evitar a insinuação de que possui a cultura que diz falar" (ADORNO, 1998, p. 07). Tal afirmação expõe a permanência de um modelo de cultura dogmático, no qual o leitor especialmente o aluno - não pode questionar.

A cultura só é verdadeira quando implicitamente crítica, e o espírito que se esquece disso vinga-se de si mesmo nos críticos que ele próprio cria. A crítica é um elemento inalienável da cultura, repleta de contradições e, apesar de toda a sua inverdade, ainda é tão verdadeira quanto não-verdadeira é a cultura. A crítica não é justa quando destrói - esta ainda seria sua melhor qualidade -, mas quando, ao desobedecer, obedece. (ADORNO, 1998, p. 11).

Nessa perspectiva, é importante salientar aqui a necessidade de uma visão crítica, mas uma crítica que não atue em um espaço dúbio de afirmação e contestação que acaba por sustentar aquilo que condena. Cabe enfatizar que a crítica ao modelo de exclusão acaba voltando-se contra si mesmo ao se propor a incluir tendo em vista uma noção homogeneizadora. Nas palavras de Adorno é o aspecto crítico que estabelece a própria noção de cultura, quando pensada em uma construção social imersa em suas dicotomias e contradições. A partir dessas reflexões, pode-se dizer que o que se busca é que o leitor possa construir seu próprio cânone, sua própria forma de leitura, dialogando com a tradição e a cultura, destruindo-a e reconstruindo-a cotidianamente.

\section{Referências}

ADORNO, Theodor. Educação e Emancipação. Tradução e Introdução: Wolfgang Leo Maar. São Paulo: Paz e Terra, 1995.

. Teoria da semicultura. In: Revista Educação \& Sociedade. Campinas: Papirus, Ano XVII, dez. 1996. 
Crítica cultural e sociedade. In;

. Prismas. Tradução: Augustin

Wernet e Jorge Mattos Brito de Almeida. São Paulo: Ática, 1998.

FREIRE, Paulo. Pedagogia da Autonomia: Saberes necessários à prática educativa. São Paulo: Paz e Terra, 1996.

. Pedagogia do Oprimido. Rio de Janeiro, Paz e Terra, 2005.

GADAMER, Hans-Georg. Hermenêutica da obra de arte. Seleção e tradução: Marco Antonio Casanova. São Paulo: Martins Fontes, 2010.

GADOTTI, Moacir. História das ideias pedagógicas. 8. ed. São Paulo: Ática, 2001.

KILPATRICK, William Heard. A filosofia da educação de Dewey. In: Revista Brasileira de Estudos Pedagógicos. Vol XIX, n. 49, 1953. Disponível em: $<$ http://www.dominiopublico.gov.br/download/texto/me001657.pdf >. Acesso em: 18 jul. 2011.

MORAES, Maria Cândida. O paradigma educacional emergente. Campinas, SP: Papirus, 1997.

OLIVEIRA, Avelino da Rosa. Exclusão Social. In: STRECK, Danilo R.; REDIN, Euclides; ZITKOISKE, Jaime José. (Orgs.). Dicionário Paulo Freire. 2. ed. Belo Horizonte: Autêntica Editora, 2010.

QUINTANA, Mario. Poesia completa. Rio de Janeiro: Nova Aguilar, 2005.

REIS, Roberto. Cânon. In: JOBIM, José Luís (Org.). Palavras da crítica. Rio de Janeiro: Imago, 1992.

SOARES, Magda Becker. As condições sociais da leitura: uma reflexão em contraponto. In: ZILBERMAN, Regina \& SILVA, Ezequiel (Org). Leitura: Perspectivas Interdisciplinares, 5. ed. São Paulo: Ática, 2000. 